\title{
GRAV3D Validation using Generalized Cross- Validation (GCV) Algorithm by Lower Bounds Approach for 3D Gravity Data Inversion
}

\author{
Aryono Adhi $^{1}$, Wahyudi ${ }^{2}$, Wiwit Suryanto ${ }^{3}$, Muh Sarkowi ${ }^{4}$ \\ ${ }^{1}$ Doctoral Programme Physics Departement, Faculty of Mathematics and Natural Sciences, \\ Universitas Gadjah MadaYogyakarta, Indonesia \\ ${ }^{2,3}$ Physics Departement, Faculty of Mathematics and Natural Sciences, \\ Universitas Gadjah Mada Yogyakarta, Indonesia \\ ${ }^{4}$ Geophysics Engineering Departement, Faculty of Engineering, Universitas Lampung, Indonesia \\ Email: ${ }^{2}$ aryono_adhi@yahoo.com,aryono.adhi@mail.ugm.ac.id, ${ }^{2}$ wahyudi@ugm.ac.id, \\ ${ }^{3}$ ws@ugm.ac.id, ${ }^{4}$ sarkov323@unila.ac.id
}

\begin{abstract}
The completion of gravitational data inversion results in a smooth recovered model. GRAV3D is one software that can be used to solve 3D inversion problems of gravity data. Nevertheless, there are still fundamental problems related to how to ensure the validity of GRAV3D to be used in 3D inversion. One approach used is to use lower bounds as inversion parameters. In this study lower bounds are set from $10^{-1}$ to $10^{-12}$. The results obtained show that the use of lower bounds decreases resulting in a larger data misfit which means that the more data that meets the tolerance calculation, the better-recovered model produced.
\end{abstract}

Keywords: GRAV3D, 3D Inversion, Validation, Lower Bounds

\section{INTRODUCTION}

Gravity data inversion modeling is a direct interpretation method that results in recovered models obtained based on gravity anomaly data with the boundary conditions assumed in the initial model. Gravity data inversion modeling is a problem determining the distribution of density in the earth from some gravity measurement data carried out on the surface of the earth GRAV3D (made by the UBC Geophysical Inversion Facility, Department of Earth and Ocean Sciences, University of British Columbia) is one of the gravity data inversion modeling programs. Modeled the earth by using a number of rectangular cells of density and then the final density distribution is obtained by minimizing the function of the objective model to adjust between the model and the field gravity data. The problem that arises is that there is no discussion about the validity of the GRAV3D program before it can be used for gravity data inversion modeling. Validation of the GRAV3D program must be done to obtain the validity and reliability of the recovered models obtained as a result of inversion[1], [2] There is a possibility of obtaining the validity of the UBC-GIF GRAV3D program through two approaches (i) a reference model (mref) and (ii) lower and upper bound models that define the minimum and maximum values, which will determine the cell value in the mesh 
until the recovered model is obtained smooth. [3]. The solution of 3D inversion with GCV techniques through the determination of the lower limit can be applied by taking into account the misfit that must be achieved should be within the rough range $0.5 * \mathrm{~N}-5.0 * \mathrm{~N}$, being $\mathrm{N}$ the number of data [4], [5]. The generalized crossvalidation $(\mathrm{GCV})$ technique was chosen for the second invasion due to its effectiveness with data sets that have good spatial coverage and positive anomalies [6].

\section{METHODS}

The solution to the inversion problem using the GRAV3D program is the problem of finding density $\rho_{(r)}$ which minimizes data misfit according to noise. The solution involves the solution of the equation $\emptyset(\rho)=\emptyset_{d}+\mu \emptyset_{m}$ where $\mu \epsilon[0, \propto]$ is the regularization parameter that controls the data misfit and the recovered model in the form of an objective function $\emptyset_{m}$. The numerical solution of the objective function $\emptyset_{m}$ can be written

$$
\phi_{m(\rho)}=\left\|\boldsymbol{W}_{m}\left(\rho_{(\boldsymbol{r})}-\rho_{o}\right)\right\|^{2}
$$

where $\rho_{(r)}$ and $\rho_{o}$ are vectors $\mathrm{M}$ which state the recover and reference models. The magnitude $\vec{\rho}$ that is used in the calculation to obtain a numerical solution objective function $\emptyset_{m}$ has a lower and upper bounds in the form of an equation

$$
\vec{\rho}_{\text {min }} \leq \vec{\rho} \leq \vec{\rho}_{\text {max }}
$$

where $\vec{\rho}_{\text {min }}$ and $\vec{\rho}_{\text {min }}$ vector that contains lower and upper bounds on model values.

Validation of GRAV3D gravity data inversion program is done through stages:

1. Using the initial modeling program with the MeshTools3D program

2. Forward modeling to get the initial model gravity response

3. The preparation of synthetic gravity data through the addition of Gaussian distributed errors to the initial model gravity response data

4. Inversion of synthetic gravity data using the GRAV3D program by repeatedly determining the lower bound of the recovered model until the recovered model is obtained

\section{RESULTS AND DISCUSSION}

Preparation of the initial model using MeshTools3D with the initial model parameters as seen in table 1 and table 2 . The initial model parameters used produce the initial model as illustrated in Figure 1. The initial model is described as 2 ellipsoid balls of different densities namely $2 \mathrm{gr} / \mathrm{cm}^{3}$ dan $2,5 \mathrm{gr} / \mathrm{cm}^{3}$.

Table 1. Parameter for ellipsoid (1) initial model

\begin{tabular}{lcr}
\hline block & 1 \\
\hline density & 2 & gr/cm3 \\
type & $\begin{array}{c}\text { ellipsoid } \\
\text { Coordinates (m) }\end{array}$ \\
X & 480 & 780 \\
Y & 240 & 540 \\
$\mathrm{Z}$ & -50 & -370 \\
\hline
\end{tabular}


Table 2. Parameter for ellipsoid (2) initial model

\begin{tabular}{lcr}
\hline block & 2 \\
\hline density & 2,5 & $\mathrm{gr} / \mathrm{cm} 3$ \\
type & $\begin{array}{c}\text { ellipsoid } \\
\text { Coordinates (m) }\end{array}$ \\
$\mathrm{X}$ & 520 & 820 \\
$\mathrm{Y}$ & 200 & 500 \\
$\mathrm{Z}$ & -50 & -370 \\
\hline
\end{tabular}

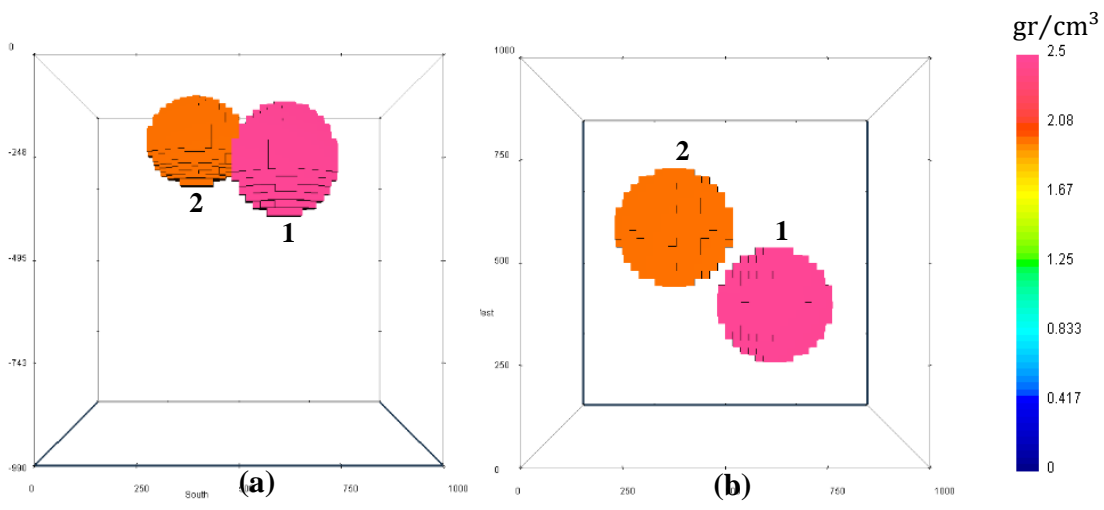

Figure 1. The initial model in 3D that was compiled using the MeshTools3d software (a) side view, (b) top view.

The gravity response of the initial model is obtained by using the gzfor 3 d.exe program as illustrated in Figure 2.

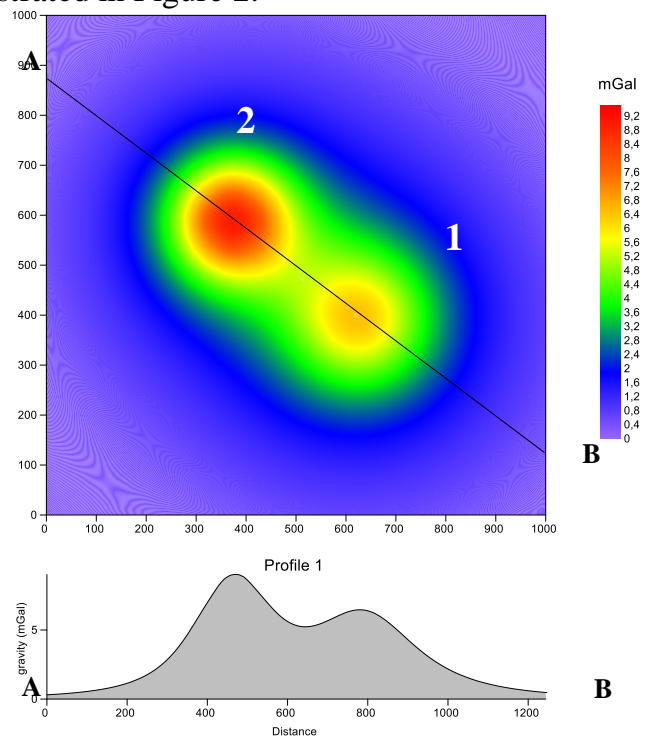

Figure 2 . The initial model gravity response in $3 \mathrm{D}$ compiled using the MeshTools3d software is obtained with the gzfor3d.exe program. 


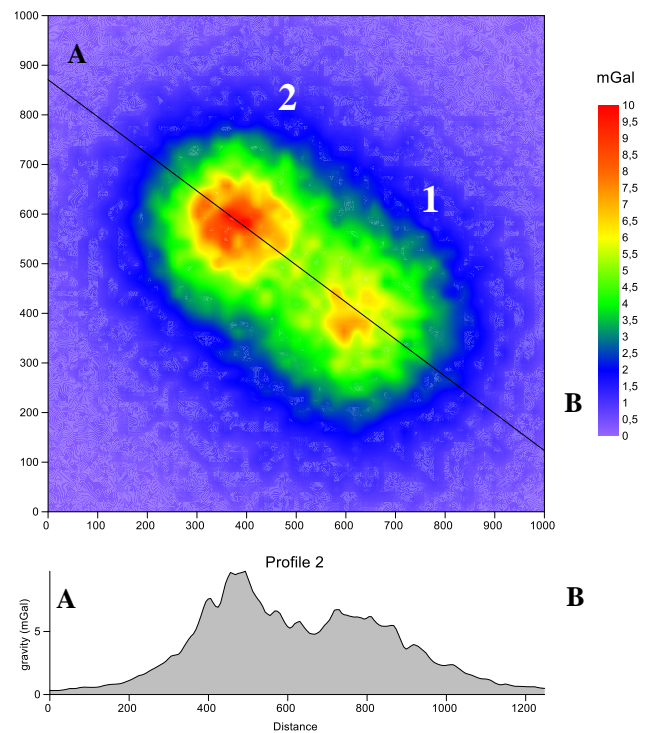

Figure 3. Gravity response with a $0.02 \mathrm{mGal}$ Gaussian error of the initial model in 3D compiled using the MeshTools3d software obtained with the gzfor3d.exe program

The next stage is synthetic gravity data arranged through the addition of Gaussian distributed errors in the initial model gravity response data. The gravity response of the initial model is then added by a $0.02 \mathrm{mGal}$ Gaussian error which is treated as synthetic gravity data to test the validity of the GRAV3D program (Figure 3).

Inversion of synthetic gravity data using the GRAV3D program is done through the determination of the lower bounds starting at $10^{-1}$ to $10^{-12} \mathrm{gr} / \mathrm{cm}^{3}$ to get the recovered model repeatedly until a smooth recovered model is obtained. The recovered model produced as the final result is illustrated in Figure 4. 


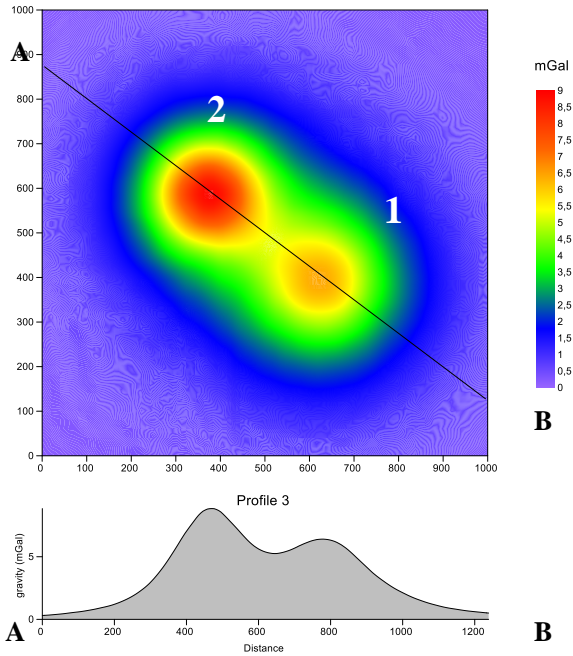

Figure 4. The gravity response of the recovered model in inversion 3D using the GRAV3D software generated for the lower bound $10^{-12}$

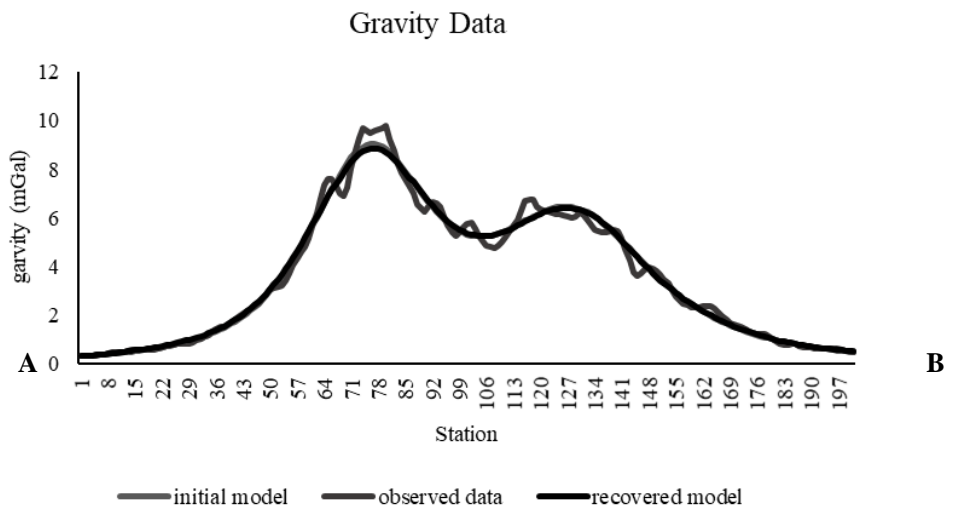

Figure 5. The fitting curve of the gravity profile obtained for the three models

The correlation coefficient produced between the initial model gravity response profile and gravity prediction ranges from 0.999. Models recovered in 3D inversion results using GRAV3D software are illustrated in Figure 6. 


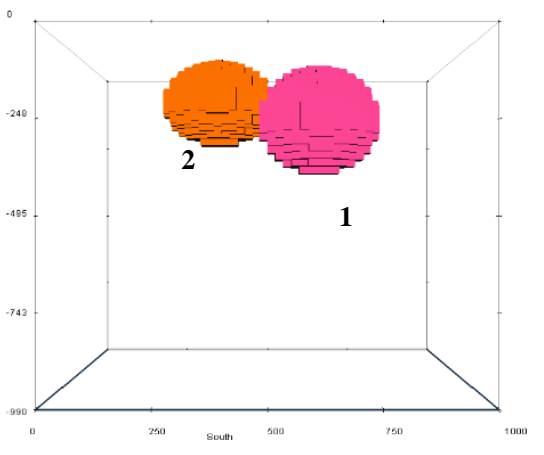

(a)

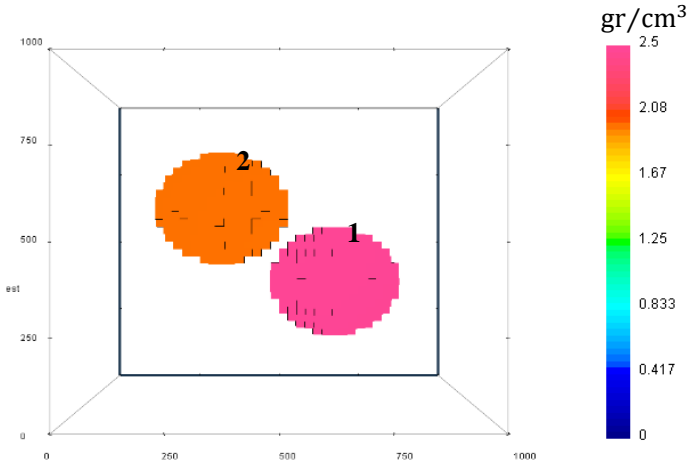

(b)

Figure 6. Model recovered in 3D inversion using the GRAV3D software (a) side View, (b) top view.

Table 3. Numerical solution to get the recovered model from GRAV3D inversion using the GCV algorithm

\begin{tabular}{ccccccccc}
\hline $\begin{array}{c}\text { lower } \\
\text { bounds }\end{array}$ & iteration & $\begin{array}{c}\text { barrier } \\
\text { parameter }\end{array}$ & $\begin{array}{c}\text { CG } \\
\text { iteration }\end{array}$ & $\begin{array}{c}\text { step } \\
\text { length }\end{array}$ & $\begin{array}{c}\text { achieved } \\
\text { misfit }\end{array}$ & $\begin{array}{c}\text { model } \\
\text { norm }\end{array}$ & $\begin{array}{c}\text { total } \\
\text { objective }\end{array}$ & $\begin{array}{c}\text { barrier } \\
\text { norm }\end{array}$ \\
\hline $1, \mathrm{E}-01$ & 7 & $3,61 \mathrm{E}-04$ & 165 & $3,88 \mathrm{E}-01$ & $2,13 \mathrm{E}+03$ & $6,88 \mathrm{E}+02$ & $2,69 \mathrm{E}+03$ & $3,17 \mathrm{E}+05$ \\
$1, \mathrm{E}-02$ & 10 & $1,18 \mathrm{E}-04$ & 124 & $4,22 \mathrm{E}-01$ & $2,23 \mathrm{E}+03$ & $7,34 \mathrm{E}+02$ & $2,83 \mathrm{E}+03$ & $5,07 \mathrm{E}+05$ \\
$1, \mathrm{E}-03$ & 13 & $3,84 \mathrm{E}-05$ & 204 & $4,17 \mathrm{E}-01$ & $2,26 \mathrm{E}+03$ & $7,57 \mathrm{E}+02$ & $2,88 \mathrm{E}+03$ & $6,29 \mathrm{E}+05$ \\
$1, \mathrm{E}-04$ & 20 & $1,05 \mathrm{E}-05$ & 285 & $2,63 \mathrm{E}-01$ & $2,28 \mathrm{E}+03$ & $7,68 \mathrm{E}+02$ & $2,91 \mathrm{E}+03$ & $7,17 \mathrm{E}+05$ \\
$1, \mathrm{E}-05$ & 14 & $5,58 \mathrm{E}-05$ & 173 & $2,72 \mathrm{E}-01$ & $2,81 \mathrm{E}+03$ & $1,32 \mathrm{E}+03$ & $3,90 \mathrm{E}+03$ & $9,04 \mathrm{E}+05$ \\
$1, \mathrm{E}-06$ & 26 & $4,32 \mathrm{E}-05$ & 512 & $2,06 \mathrm{E}-01$ & $2,79 \mathrm{E}+03$ & $1,42 \mathrm{E}+03$ & $3,96 \mathrm{E}+03$ & $1,15 \mathrm{E}+06$ \\
$1, \mathrm{E}-07$ & 44 & $3,97 \mathrm{E}-05$ & 1117 & $1,14 \mathrm{E}-01$ & $2,79 \mathrm{E}+03$ & $1,44 \mathrm{E}+03$ & $3,97 \mathrm{E}+03$ & $1,38 \mathrm{E}+06$ \\
$1, \mathrm{E}-08$ & 5 & $2,45 \mathrm{E}-05$ & 571 & $6,46 \mathrm{E}-03$ & $2,98 \mathrm{E}+03$ & $5,37 \mathrm{E}+03$ & $7,39 \mathrm{E}+03$ & $1,70 \mathrm{E}+06$ \\
$1, \mathrm{E}-09$ & 5 & $2,22 \mathrm{E}-05$ & 215 & $5,76 \mathrm{E}-03$ & $2,73 \mathrm{E}+03$ & $6,53 \mathrm{E}+03$ & $8,09 \mathrm{E}+03$ & $1,92 \mathrm{E}+06$ \\
$1, \mathrm{E}-10$ & 4 & $2,04 \mathrm{E}-05$ & 133 & $1,35 \mathrm{E}-02$ & $2,73 \mathrm{E}+03$ & $6,85 \mathrm{E}+03$ & $8,35 \mathrm{E}+03$ & $2,13 \mathrm{E}+06$ \\
$1, \mathrm{E}-11$ & 3 & $1,98 \mathrm{E}-05$ & 16 & $1,00 \mathrm{E}+0($ & $2,74 \mathrm{E}+03$ & $7,28 \mathrm{E}+03$ & $8,72 \mathrm{E}+03$ & $2,29 \mathrm{E}+06$ \\
$1, \mathrm{E}-12$ & 3 & $1,82 \mathrm{E}-05$ & 14 & $1,00 \mathrm{E}+0($ & $2,74 \mathrm{E}+03$ & $7,28 \mathrm{E}+03$ & $8,72 \mathrm{E}+03$ & $2,51 \mathrm{E}+06$ \\
\hline
\end{tabular}

Numerical solution to get the recovered model from GRAV3D inversion using the GCV algorithm with the lower bounds starting at $10^{-1}$ to $10^{-12} \mathrm{gr} / \mathrm{cm}^{3}$ shown in table 3 . At lower bounds $10^{-1} \mathrm{gr} / \mathrm{cm}^{3}$ achieved misfit $2,3110^{3}$ the data misfit value gets bigger to lower bounds $10^{-11} \mathrm{gr} / \mathrm{cm}^{3}$ at achieved misfit $2,7410^{3}$. The results obtained show that the recovered model obtained is equivalent to the initial model produced. This result is reinforced by the results obtained through a fitting curve which has a correlation of 0.999 as shown in Figure 5.

\section{CONCLUSION}

The approach used by using lower bounds as an inversion parameter can be used to ensure the validity of the GRAV3D program. In this study lower bounds are set from $10^{-1}$ to $10^{-12} \mathrm{gr} / \mathrm{cm}^{3}$ produce a larger data misfit which means more data that meets the tolerance calculation means that the recovered model produced is finer with a stable data misfit value at $2,7410^{3}$. 


\section{REFERENCES}

[1] MacQueen, P. G. (2011). Forward Modeling to Assess and Improve Gravity Network Geometry at Kilauea Volcano, Hawaii. Oregon Undergraduate Research Journal, 1(1), 24-44.

[2] MacQueen, P. G. (2013). Geophysical Investigations of Magma Plumbing Systems at Cerro Negro volcano, Nicaragua.

[3] Mahmoodi, O., Smith, R. S., \& Spicer, B. (2017). Using Constrained Inversion of Gravity and Magnetic Field to Produce a 3D Litho-prediction Model. Geophysical Prospecting, 65(6), 1662-1679.

[4] UBC. (2005). GRAV3D Version 3.0 A Program Library for Forward Modelling and Inversion of Gravity Data over $3 D$ Structures. Vancouver. British Columbia.

[5] Deng, Y., Zhang, Z., Badal, J., \& Fan, W. (2014). 3-D Density Structure Under South China Constrained by Seismic Velocity and Gravity Data. Tectonophysics, 627, 159-170.

[6] Zurek, J., \& Williams-Jones, G. (2013). The Shallow Structure of Kīlauea Caldera from High-resolution Bouguer gravity and Total Magnetic Anomaly Mapping: Insights into Progressive Magma Reservoir Growth. Journal of Geophysical Research: Solid Earth, 118(7), 3742-3752. 